\title{
Professional Physical Scientists Display Tenacious Teleological Tendencies: Purpose-Based Reasoning as a Cognitive Default
}

\author{
Deborah Kelemen, Joshua Rottman, and Rebecca Seston \\ Boston University
}

\begin{abstract}
Teleological explanations account for objects and events by reference to a functional consequence or purpose. Although they are popular in religion, they are unpopular in science: Physical scientists in particular explicitly reject them when explaining natural phenomena. However, prior research provides reasons to suspect that this explanatory form may represent a default explanatory preference. As a strong test of this hypothesis, we explored whether physical scientists endorse teleological explanations of natural phenomena when their information-processing resources are limited. In Study 1, physical scientists from top-ranked American universities judged explanations as true or false, either at speed or without time restriction. Like undergraduates and age-matched community participants, scientists demonstrated increased acceptance of unwarranted teleological explanations under speed despite maintaining high accuracy on control items. Scientists' overall endorsement of inaccurate teleological explanation was lower than comparison groups, however. In Study 2, we explored this further and found that the teleological tendencies of professional scientists did not differ from those of humanities scholars. Thus, although extended education appears to produce an overall reduction in inaccurate teleological explanation, specialization as a scientist does not, in itself, additionally ameliorate scientifically inaccurate purpose-based theories about the natural world. A religion-consistent default cognitive bias toward teleological explanation tenaciously persists and may have subtle but profound consequences for scientific progress.
\end{abstract}

Keywords: teleology, design, explanation, dual processing, agency

Supplemental materials: http://dx.doi.org/10.1037/a0030399.supp

"Inquiry into final causes is sterile and like a virgin consecrated to God, produces nothing."

—Francis Bacon, De Augmentis Scientarum, Book III

Aristotle classically argued that an adequate scientific response to any "why" question about nature requires reference to four types of causes. Significant among these was the "efficient cause," the antecedent source of an object or event. But although efficient causes are familiar as the guiding focus of scientific discovery and explanation in the contemporary physical sciences, Aristotle himself viewed them as secondary when it came to adequately accounting for the existence and properties of natural objects. For him, the pinnacle of explanation for all living and nonliving natural phenomena lay with identification of the "final cause"

This article was published Online First October 15, 2012.

Deborah Kelemen, Joshua Rottman, and Rebecca Seston, Department of Psychology, Boston University.

This research is an output of the Cognition, Religion and Theology Project at the University of Oxford funded by the John Templeton Foundation. It was also funded by National Science Foundation (NSF) DRL1007984 (awarded to Deborah Kelemen) and NSF Graduate Research Fellowship DGE-0741448 (awarded to Joshua Rottman). The views expressed are those of the authors. Many thanks to Holly Jacobs for data collection assistance, Matt Rogers of Colorado State University for advice, and the BU Child Cognition Lab research assistants for all of their help.

Correspondence concerning this article should be addressed to Deborah Kelemen, Boston University, Department of Psychology, 64 Cummington Mall, Boston, MA 02215. E-mail: dkelemen@bu.edu or "the end that for the sake of which a thing is done (telos)," in other words, the object or event's goal or function. Thus, for Aristotle, leaves on plants exist in order to provide shade, flames flicker because their natural end point lies heavenwards, and water exists in order to sustain life on Earth (see Aristole, c. $350 \mathrm{BC} / 1930)$.

Aristotle's appeal to goals and functions as a basis of explanation, what is nowadays termed teleological explanation, was promiscuous. He viewed teleology as a fundamental and general principle of explanation broadly applicable to living and nonliving natural phenomena of all kinds. This liberality made sense in context of his underlying theoretical assumptions about the general makeup of the cosmos: He viewed it as akin to a living organism. Just as an organism's component biological processes and organs seem intrinsically charged with the purpose to maintain the vital organism as a whole, so natural entities act and function with the end of preserving the integrity of the universe. Physical scientists nowadays reject these animistic causal assumptions as well as the other empirically unverifiable metaphysical beliefs that have historically licensed teleological explanation in science (e.g., the theory that nature is an artifact of divine design). This rejection began in the Renaissance, and with it, as Bacon's epigram suggests, teleological explanation increasingly fell into disrepute. The critique was that it is logically flawed and nonexplanatory because, stripped of any animistic or intentional theoretical underpinnings, statements like "atoms react in order to maintain stability" violate temporal constraints by treating an entity's consequence as if it could be its own cause in backward causal fashion. 
More recently, attempts have been made to reestablish the scientific legitimacy of teleological explanation, at least for evolutionary biology (e.g., Allen, Bekoff, \& Lauder, 1998; Hempel \& Oppenheim, 1948; Mayr, 1985; Nagel, 1961; Neander, 1991; Perlman, 2004; Sober, 1984; Wright, 1976). ${ }^{1}$ Nevertheless, outside of those domains in which intentional causality can be implicitly assumed (e.g., intentionally designed artifacts and goal-directed behavior), the status of teleological explanation in science remains highly controversial, most markedly in the physical sciences: In such disciplines, explanatory references to the goals and purposes of inanimate natural phenomena are not only tainted by quasireligious overtones of design and animism but also deemed superfluous because all phenomena can be more straightforwardly mechanistically explained by reference to antecedent physicalcausal conditions (e.g., Barrow \& Tipler, 1986; Burtt, 1932; Corey, 1993; Perlman, 2004; Talanquer, 2007; White, 1992; Wicken, 1981). But although contemporary physical scientists might explicitly reject teleological explanation, it is unclear whether its influence on thought and scientific inquiry is really so easy to escape. The question at the heart of the present article is, can it ever be escaped?

Contemporary chemistry and physics may have been purged of teleological explanation, but that has not undermined its appeal among populations that are relatively untutored in science. In fact, a broad tendency to see purpose in nature may run quite deep in the human psyche. A body of research has demonstrated that a bias toward teleological explanation is established from quite early in development. Young children are "promiscuously teleological," displaying strong, generalized preferences for teleological rather than physical-causal explanations of living and nonliving natural objects from preschool (DiYanni \& Kelemen, 2005; Kelemen, 1999a, 1999b, 2003; Kelemen \& DiYanni, 2005; but see Greif, Kemler Nelson, Keil, \& Gutierrez, 2006; Keil, 1992). Such findings are also echoed in various adult populations, suggesting children's bias is not simply a symptom of immaturity that is automatically extinguished by development. In particular, Romanian Roma adults with minimal schooling (Casler \& Kelemen, 2008) and Alzheimer's patients with degraded semantic memories (Lombrozo, Kelemen, \& Zaitchik, 2007) also display broad teleological intuitions about natural entities and their properties. Unlike undergraduates, when they are asked to choose between explanations for the existence of natural objects or their properties, they tend to endorse teleological ideas (e.g., prehistoric rocks were pointy so that animals would not sit on them and smash them) rather than physical-causal alternatives (e.g., they were pointy because material built up over time).

Taken together, these results are consistent with a proposal that teleological explanation represents something of a developmentally persistent cognitive default. This proposal breaks from traditional accounts of conceptual development, which tend to characterize conceptual change as a process of revision and replacement in which earlier intuitive theories are effectively restructured by the acquisition of more veridical scientific accounts such that they subsequently become unavailable for explanation and inference (e.g., Piaget, 1983; see also Carey, 1985, 1991; Chi, 1992; Gopnik \& Wellman, 1994). In contrast, it seems possible that a coexistence account of theory change might be more accurate: Rather than being supplanted by the elaboration of scientific theoretical ideas, it is feasible that an early arising intuitive tele- ological construal of nature might remain as a lifelong bias, which may be inhibited and concealed by later constructed beliefs, but which is never fully displaced (e.g., Dunbar, Fugelsang, \& Stein, 2007; E. M. Evans, Legare, \& Rosengren, 2011; Kelemen \& Rosset, 2009; Zaitchik \& Solomon, 2008). ${ }^{2}$ This is akin to dualprocessing models that characterize early developing intuitions as heuristics that can be increasingly overridden in later development by effortful processing, but which can nevertheless persistently reemerge in cases when intuitions are favored or forced (e.g., J. St. B. T. Evans, 2008, 2011; Kahneman, 2011; Stanovich, West, \& Toplak, 2011).

This coexistence proposal makes a clear prediction: Even highly educated individuals with substantial countervailing scientific content knowledge and intellectual bias should occasionally betray signs that they preferentially default to scientifically unwarranted teleological interpretations of natural phenomena. However, to date, a strong test of this prediction has never been conducted despite suggestive findings from college-educated populations. In earlier work, Kelemen and Rosset (2009) found that although university undergraduates favor physical-causal over teleological alternatives on the kinds of reflective reasoning tasks used to test children, they show striking tendencies to accept inaccurate teleological statements about living and nonliving natural phenomena when their cognitive resources are taxed. That is, when asked to judge explanations at speed-a manipulation that precludes inhibition of initial nonreflective explanatory reactions - undergraduates showed heightened tendencies to accept inaccurate teleological explanations $(61 \%)$ relative to their unspeeded counterparts $(52 \%)$. By contrast, their speeded responses to inaccurate control explanations revealed no equivalent levels of inaccuracy or performance decrement.

As noted, these results are suggestive evidence regarding the status of teleological explanation as a default. Nevertheless, they remain inconclusive for several reasons. First, even with exposure to multiple college-level science classes, the scientific knowledge of undergraduates is relatively weak. Indeed, independent assessments of biological and geoscience content knowledge in the undergraduates studied by Kelemen and Rosset (2009) confirmed the fragmentary nature of their understanding. Second, there is, in general, no strong reason to assume that teleological explanations should be absent from undergraduate populations. Such students

\footnotetext{
${ }^{1}$ The dominant defense of teleological explanation in evolutionary biology is the etiological argument, which proposes that it is legitimate to make statements that explain a biological trait in terms of its functional effect (e.g., hearts are for pumping blood) if that functional capacity caused an organism with a trait of that structural type to get selected during the evolutionary process (Millikan, 1989; Neander, 1991; Wright, 1976). It is unlikely that most adults engage in such mechanistically based historical assumptions when making teleological statements about biological traits and organs, however, given that natural selection is generally misunderstood as a foresightful rather than a blind process. Although biologists use teleological language routinely, it remains controversial. The distaste has prompted various attempts to strip the term teleology from the life sciences and use teleonomy instead (e.g., Mayr, 1985).

${ }^{2}$ Interpretively, then, the reason why Alzheimer's patients demonstrate promiscuous teleological beliefs is not because the degradation of their knowledge base prompts them to construct new teleological ideas resembling those once constructed in childhood but because the purpose-based explanatory preferences and beliefs that were developed in childhood never disappeared.
} 
have not necessarily adopted the reflective, normative stance that teleology is scientifically inappropriate. Unlike professional scientists, it is probable that they have not even given careful thought to the issue. Patterns in Kelemen and Rosset's findings again suggested this. Although students found teleological explanations even more appealing under cognitive load, their endorsement of teleological explanation was already over $50 \%$ when they were given time to reflect on their answers in an unspeeded condition.

In the present research, we therefore present the clearest exploration of the coexistence proposal-and the tenacious entrenchment of a teleological bias - by examining an expert population whose knowledge of physical mechanisms is unquestionable and for whom scientific physical-causal theorizing is not only privileged but normative and routine ${ }^{3}$ : professional physical scientists at high-ranking American research universities. Do physical scientists default to scientifically unwarranted teleological explanations when their abilities to censor their automatic explanatory reactions are compromised by being required to respond at speed?

To explore this, we asked academically active physical scientists to perform a speeded explanation judgment task in which they judged the correctness of warranted and unwarranted explanations of various phenomena under speeded conditions or without time limits. In addition, we also explored the potential theoretical commitments that might underpin this bias given the alternative possibility that the tendency is atheoretical and reflects a conceptually nondecomposable innate interpretive stance (e.g., Keil, 1992, 1995), modular heuristic (Atran, 1995), or basic inferential tendency triggered by structure-function fit (e.g., Lombrozo et al., 2007). With regard to the idea that the teleological bias has folk theoretical underpinnings and occurs because of underlying causal commitments promoting beliefs that natural phenomena exist for purposes, two related alternatives seem likely. One is the quasispiritual agentive theory that the Earth is a goal-directed living organism-in contemporary parlance, a cosmological belief in Mother Earth or "Gaia." The other is the notion that nature is an artifact of supernatural design — an idea that is, of course, also well represented in the major religions. Both of these kinds of theories have explicitly licensed scientific assumptions about final causation throughout history. Relevantly, recent studies have yielded evidence that both may play a role in promoting teleological beliefs: In young children, promiscuous teleology has been found to relate to beliefs about intentional design in nature (Kelemen \& DiYanni, 2005; see also Diesendruck \& Haber, 2009), and in undergraduates, evidence has suggested connections to intuitive Gaia beliefs (Kelemen \& Rosset, 2009; but see Lombrozo et al., 2007). Although it was anticipated that contemporary physical scientists would not overtly endorse the existence of Gaia or God with any particular enthusiasm, any evidence that the teleological bias is a product of agency-based causal explanatory beliefs rather than a more conceptually primitive heuristic has important implications for not only theory but also educational practice (Kelemen, 2012).

\section{Study 1}

\section{Method}

Participants. The final sample included 80 physical scientists (39 women, mean age $=36$ years, $S D=4$; mean years since
Ph.D. $=8$ years, $S D=4)$ who were actively publishing scholars in chemistry, geoscience, and physics departments at high-ranking American colleges and universities (e.g., Boston University, Brown, Columbia, Harvard, MIT, Yale). Two control populations included 179 Boston-area college undergraduates (107 women, mean age $=19$ years, $S D=1$ ) and 49 members of the Boston community who were age-matched to the scientists but held only bachelor's degrees ( 28 women, mean age $=38$ years, $S D=5$ ). Participants in all groups were native English speakers, under 45 years, and without self-reported color-blindness or dyslexia. An additional 71 participants were excluded for failing to (a) respond to at least $75 \%$ of the test items and/or (b) accurately respond to at least $80 \%$ of the control items (nine science; 51 college; 11 community). The whole study took approximately $1 \mathrm{hr}$ to complete. College undergraduates, who had the highest rate of exclusion, received experimental course credit for their participation; all other participants received a cash payment.

Procedure. Stimuli were 100 one-sentence explanations for "why things happen," presented consecutively on a laptop using PsyScope software (Cohen, MacWhinney, Flatt, \& Provost, 1993). Participants judged them as "true" or "false" using two response keys. There were 30 test sentences and 70 control sentences.

Test sentences described scientifically unwarranted teleological explanations for various natural phenomena (e.g., "The sun radiates heat because warmth nurtures life"; see Table 1 for more examples and supplementary online material for a full list). Control sentences were of four types that were included to track participants' response biases, their overall abilities to read at speed, and their accuracy at judging the truth or falsity of explanatory statements in general. They comprised 20 true causal explanations (e.g., "Conception occurs because sperm and eggs fuse together"), 10 true teleological explanations (e.g., "Children wear mittens in the winter in order to keep their hands warm"), 30 false causal explanations (e.g., "Snowflakes are white because they are symmetrical"), and 10 false teleological explanations (e.g., "Window blinds have slats so that they can capture dust"). In contrast to teleological test sentences, which involved inaccurate explanations of natural phenomena, false teleological control sentences concerned the social-conventional and artifact domains in which teleological explanation is appropriate. They were false by virtue of incongruity. To catch response strategies based on skimming sentences for content words rather than reading them fully, control sentences, like test sentences, invoked closely associated concepts throughout.

Participants in each group were randomly assigned to speeded and unspeeded conditions. In the speeded condition, participants had a maximum of 3,200 ms to respond-a speed determined, via piloting, to be two standard deviations above the average reading time for all sentences. In the unspeeded condition, participants were asked to make a judgment after careful consideration and received no time limit. In both conditions, the stimulus progressed immediately after the participant's response (or, in the speeded condition, after 3,200 $\mathrm{ms}$ had passed if the participant had not yet

\footnotetext{
${ }^{3}$ Note that these characteristics do not extend to professional biologists who habitually (and controversially) use teleological language and are therefore an ambiguous population for study (see Allen et al., 1998; Mayr, 1985; Sober, 1984).
} 
Table 1

Examples of Test and Control Sentences

\begin{tabular}{|c|c|c|}
\hline $\begin{array}{l}\text { Sentence } \\
\text { type }\end{array}$ & Subtype & Item \\
\hline \multirow[t]{5}{*}{ Test } & & $\begin{array}{l}\text { Trees produce oxygen so that animals can } \\
\text { breathe. }\end{array}$ \\
\hline & & $\begin{array}{l}\text { Germs mutate in order to become drug } \\
\text { resistant. }\end{array}$ \\
\hline & & $\begin{array}{l}\text { Moss forms around rocks in order to stop soil } \\
\text { erosion. }\end{array}$ \\
\hline & & $\begin{array}{l}\text { The Earth has an ozone layer in order to } \\
\text { protect it from UV light. }\end{array}$ \\
\hline & & $\begin{array}{l}\text { The sun makes light so that plants can } \\
\text { photosynthesize. }\end{array}$ \\
\hline \multirow[t]{4}{*}{ Control } & TT & $\begin{array}{l}\text { Women put on perfume in order to smell } \\
\text { pleasant. }\end{array}$ \\
\hline & FT & $\begin{array}{l}\text { Lamps shine brightly so that they can produce } \\
\text { heat. }\end{array}$ \\
\hline & $\mathrm{TC}$ & $\begin{array}{l}\text { Soda fizzes because carbon dioxide gas is } \\
\text { released. }\end{array}$ \\
\hline & $\mathrm{FC}$ & $\begin{array}{l}\text { Oceans have waves because they contain a lo } \\
\text { of seawater. }\end{array}$ \\
\hline
\end{tabular}

Note. $\quad \mathrm{TT}=$ true teleological $; \mathrm{FT}=$ false teleological $; \mathrm{TC}=$ true causal; $\mathrm{FC}=$ false causal.

responded). Sentences were presented consecutively in 10 tensentence blocks with a 3-s pause between blocks. Each block contained seven control items and three test items in random order. Two blocks of practice sentences were not included in analyses.

In order to explore individual differences in general susceptibility to the teleological bias, participants also completed several additional measures. People with poorer inhibitory control may generally have greater difficulties suppressing automatic intuitive reactions in favor of less intuitive, tutored responses, and so we examined whether poor inhibitory control would increase tendencies to endorse teleological ideas. Participants therefore completed a computer-based 48-item Stroop color task (Stroop, 1935) to measure inhibitory control. Their task was to quickly identify the print color of a written color word when the meaning of the written word and its print color were different (incongruent) or the same (congruent). Scores were calculated by subtracting the average reaction time to congruent items from the average reaction time to incongruent ones to create a difference score. Higher Stroop difference scores indicated lower inhibitory control and were used to examine whether Stroop scores would positively predict teleological sentence endorsement. Stroop data were not included in analyses if participants were less than $80 \%$ accurate on incongruent Stroop trials (one science, 11 college, one community).

Gaps in scientific knowledge base could also increase tendencies to endorse intuitive teleological ideas because alternative physical-causal explanations would be unavailable in individuals' semantic memories. To measure scientific knowledge, participants completed the 20-item multiple-choice Conceptual Inventory of Natural Selection (Anderson, Fisher, \& Norman, 2002) and 18 multiple-choice items of the Geoscience Concept Inventory (Libarkin \& Anderson, 2006).

Finally, in order to explore whether the tendency to explain nature in teleological terms is theoretical insofar as it derives from more basic causal intuitions about agency and design in nature (e.g., Kelemen, 2004; Kelemen \& Rosset, 2009) rather than being a primitive cognitive stance or heuristic (Atran, 1995; Keil, 1992; Lombrozo \& Carey, 2006; Lombrozo et al., 2007), we explored whether participants with stronger explicit religious beliefs in God and spiritual "Gaia" beliefs in Mother Nature showed greater susceptibility to teleological errors. Participants rated their beliefs in God and "Nature is a powerful being" on a 1 (strongly disagree) to 5 (strongly agree) Likert scale.

\section{Results}

Explanation judgment task. We first explored the effects of restricted processing on endorsements of unwarranted teleological explanations. A 2 (condition: speeded vs. unspeeded) $\times 3$ (group: scientists vs. community vs. college) analysis of variance (ANOVA) on inaccurate test sentence endorsements ${ }^{4}$ revealed main effects of group, $F(2,302)=58.59, p<.001, \eta^{2}=.28$, and condition, $F(1,302)=22.57, p<.001, \eta^{2}=.07$, with no interaction. Planned post hoc analyses exploring the group effect revealed that, replicating prior findings (Kelemen \& Rosset, 2009), college participants displayed substantial acceptance of unwarranted teleological explanations of natural phenomena $(M=51 \%$, $S D=21 \%$ ), with community participants endorsing them to an equivalent degree $(M=47 \%, S D=22 \% ; p=.23)$. The physical scientists' general acceptance for teleological explanations $(M=$ $22 \%, S D=19 \%$ ) was lower than that of both control groups ( $p<$ .001 for both). The pattern therefore suggests that maturation does not decrease the general appeal of teleological explanation, but becoming a scientist does.

Despite differences between group means, post hoc analyses of the condition effect revealed that all participant groups, including the physical scientists, showed higher acceptance of inaccurate teleological explanations under speed. Notably, speeded scientists' teleological endorsements $(M=29 \%, S D=22 \%)$ were approximately twice those of their unspeeded colleagues $(M=15 \%$, $S D=14 \%$ ). Indeed, as demonstrated by the lack of statistical interaction between group and condition, the effect of restricted processing remained constant across group differences in education and age (see Figure 1). In short, even if years of higher education generally reduce scientifically unwarranted teleological explanations of natural phenomena, an intuitive bias in favor of teleological explanations resolutely perseveres. Physical scientists reveal this tendency when their cognitive resources are taxed.

We examined control sentence performance to see whether the effect of speeded processing on test sentence endorsement occurred because participants experienced generalized difficulties in reading and evaluating any kind of explanation at speed. A 2 (condition: speeded vs. unspeeded) $\times 2$ (sentence type: test vs. control) $\times 3$ (group: scientists vs. community vs. college)

\footnotetext{
${ }^{4}$ Test sentences were reviewed by two independent scientific experts prior to testing and deemed inaccurate. However, during testing, three test sentences received unexpectedly high levels of endorsement by unspeeded scientists. Six independent scientific experts were then interviewed about all test items but produced no consensus view on these three sentences (while also displaying difficulty justifying judgments that the statements were accurate, whereas other similarly worded statements were not). To avoid potentially inflating any report of teleological bias, we have excluded these sentences from all analyses. It should be noted that including them does not alter the pattern of results reported here. All of the removed sentences could be regarded as implying that nature self-regulates in a Gaia-like fashion (see Study 2, Kelemen \& Rosset, 2009).
} 

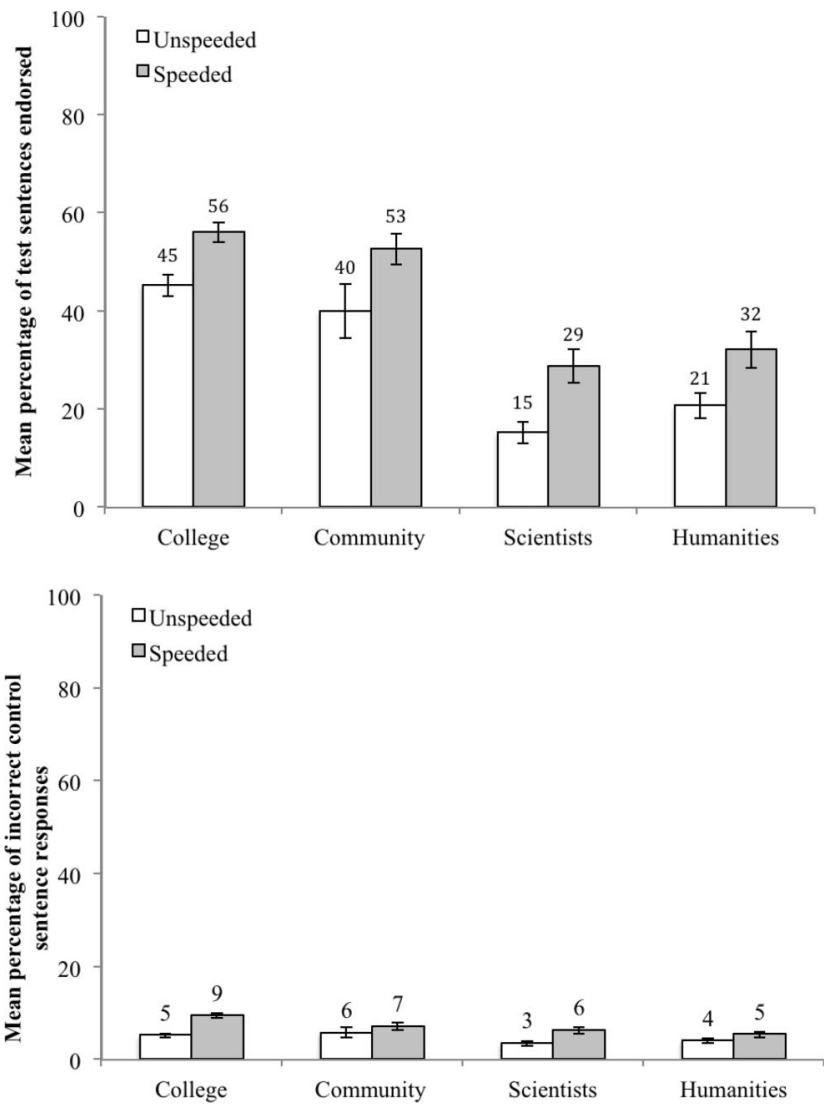

Figure 1. Mean percentage of unwarranted teleological test sentences accepted (top panel) and incorrect control sentence responses (bottom panel) by college, community, and scientist participants in Study 1 and humanities participants in Study 2. Error bars represent standard errors of the means.

ANOVA on incorrect responses revealed a main effect of sentence type, $F(1,302)=720.50, p<.001, \eta^{2}=.71$. This indicated that participants erred more often on test sentences $(M=42 \%, S D=$ $24 \%)$ than on control sentences $(M=7 \%, S D=5 \%)$, where error rates were very low. Analysis of a significant Sentence Type $\times$ Condition interaction, $F(1,291)=18.61, p<.001, \eta^{2}=.06$, was also consistent with the pattern above: Whereas speeded responding created substantial disparities in accuracy on test sentences (14\% difference), the disparity on control sentences was not comparable ( $3 \%$ difference). The overall pattern of these findings confirms that participants' heightened level of error on speeded teleological test sentences was not a result of general difficulties in reading and judging all kinds of explanation at speed.

Individual differences. Within each participant group, individuals randomly assigned to speeded and unspeeded conditions did not differ on scientific knowledge, inhibitory control, or personal belief scores. Conditions were therefore collapsed for all subsequent analyses.

One-way ANOVAs revealed that, as expected, a group difference emerged with respect to biological content knowledge, $F(2$, $305)=57.75, p<.001, \eta^{2}=.28$, and geoscience content knowledge, $F(2,305)=55.38, p<.001, \eta^{2}=.27$. Post hoc analyses confirmed that physical scientists had more biological and geoscience content knowledge than either college or community participants $(p s<.001)$ who did not differ from each other ( $p$ s > .48). Importantly, however, despite prior research suggesting relationships between inhibitory control and education (Ganguli et al., 2010; Stern et al., 1994), the groups did not differ in their inhibitory control capacities, $F(1,292)=0.29, p=.75$. Physical scientists' lower overall level of teleological endorsement was therefore not a result of having enhanced abilities to inhibit natural, automatic responses.

Next, we examined whether the groups differed in their beliefs in God and Mother Nature and found that they did: God, $F(2,305)=14.78, p<.001, \eta^{2}=.09$; Mother Nature, $F(2$, $305)=43.20, p<.001, \eta^{2}=.22$. Physical scientists were disinclined to believe in both, giving lower ratings of explicit belief than both college and community participant groups ( $p \mathrm{~s}<$ $.003)$, who did not differ from each other $(p>.26$; see Table 2$)$. In sum, physical scientists who, as a group, were less prone to endorse inaccurate teleological explanations also had a greater scientific knowledge base and lower explicit beliefs in God and Mother Nature.

Because the college and community samples did not differ on any measure, their data were collapsed for individual-differences analyses within each group (henceforth, the combined group is referred to as $C C$ ). As Table 3 shows, linear regressions of scientific content knowledge and inhibitory control on unwarranted teleological sentence endorsement (controlling for the effects of condition) revealed that, in both the $\mathrm{CC}$ and scientist groups, poorer scientific knowledge predicted individual susceptibility to teleological error $\left(\mathrm{CC}: R^{2}=.17, p<.001\right.$; scientists: $R^{2}=.51$, $p<.001)$. Among CC participants, weaknesses in both biological knowledge and geoscience knowledge increased test sentence en-

Table 2

Group Means (and Standard Deviations) for Predictor Variables

\begin{tabular}{lccccc}
\hline \multicolumn{1}{c}{ Group } & $\begin{array}{c}\text { Biological } \\
\text { knowledge }\end{array}$ & $\begin{array}{c}\text { Geoscience } \\
\text { knowledge }\end{array}$ & $\begin{array}{c}\text { Inhibitory } \\
\text { control }\end{array}$ & $\begin{array}{c}\text { Belief } \\
\text { in God }\end{array}$ & $\begin{array}{c}\text { Belief in } \\
\text { Mother Nature }\end{array}$ \\
\hline College & $59(19)$ & $50(16)$ & $168(116)$ & $3.3(1.4)$ & $3.7(1.2)$ \\
Community & $61(20)$ & $48(17)$ & $179(126)$ & $3.0(1.5)$ & $3.9(1.4)$ \\
Scientists & $84(16)$ & $73(19)$ & $178(115)$ & $2.2(1.5)$ & $2.2(1.5)$ \\
Humanities & $76(17)$ & $49(14)$ & $193(127)$ & $2.2(1.4)$ & $2.5(1.6)$ \\
\hline
\end{tabular}

Note. Predictor variables are as follows: percentage correct on the Conceptual Inventory of Natural Selection (Anderson et al., 2002) and Geoscience Concept Inventory (Libarkin \& Anderson, 2006); Stroop inhibitory control score (milliseconds); Belief in God and Mother Nature $(1=$ Strongly disagree; $5=$ Strongly agree $)$. 
Table 3

Linear Regression Exploring the Effects of Scientific Content Knowledge and Inhibitory Control on Unwarranted Teleological Sentence Endorsement, Controlling for Condition

\begin{tabular}{|c|c|c|c|c|c|c|c|c|c|}
\hline \multirow[b]{2}{*}{ Variable } & \multicolumn{3}{|c|}{ College/Community } & \multicolumn{3}{|c|}{ Scientists } & \multicolumn{3}{|c|}{ Humanities } \\
\hline & $\beta$ & $t(211)$ & $p$ & $\beta$ & $t(74)$ & $p$ & $\beta$ & $t(64)$ & $p$ \\
\hline Condition & 0.30 & 4.75 & .000 & 0.34 & 4.07 & .000 & 0.27 & 2.60 & .012 \\
\hline Biological knowledge & -0.16 & -2.25 & .025 & -0.57 & -6.30 & .000 & -0.38 & -3.48 & .001 \\
\hline Geoscience knowledge & -0.21 & -2.93 & .004 & -0.14 & -1.52 & .133 & -0.20 & -1.88 & .065 \\
\hline Inhibitory control & -0.06 & -0.95 & .346 & -0.09 & -1.03 & .307 & 0.05 & 0.49 & .628 \\
\hline
\end{tabular}

Note. All models significantly predicted individual susceptibility to teleological error: college and community samples $R^{2}=.17, p<.001$; scientists $R^{2}=.51, p<.001$; humanities $R^{2}=.31, p<.001$.

dorsements. Among physical scientists, it was poorer biological knowledge alone.

As Table 4 shows, further regressions of explicit beliefs in God and Mother Nature on unwarranted teleological sentence endorsement (controlling for the effects of condition) were significant for both groups $\left(\mathrm{CC}: R^{2}=.16, p<.001\right.$; scientists: $R^{2}=.30, p<$ .001). Among CC participants, beliefs in both God and Mother Nature predicted unwarranted teleological endorsements. Belief in Mother Nature alone predicted scientists' endorsements. Patterns of intercorrelation with beliefs in God and Mother Nature revealed the quasi-religious nature of scientists' Mother Nature beliefs $(R=$ $.29, p=.01)$. In short, individuals with more incomplete scientific content knowledge and stronger intuitions about agentive forces influencing nature were more prone to teleological error.

\section{Discussion}

Study 1 demonstrated that even physical scientists, despite their extensive scientific training, routine adoption of physical-causal explanations, and anti-teleological norms, default to scientifically inaccurate teleological explanations when their cognitive resources are limited. Although enhanced scientific content knowledge reduced overall tendencies to endorse unwarranted teleological explanations, accomplished physical scientists were attracted to teleological explanations of natural phenomena when they did not have time to censor their own thinking. This was particularly the case among individuals with weaker biological content knowledge, and, consistent with the proposal that the teleological bias is theoretically based, it was also the case among those with stronger quasi-religious beliefs in "Mother Nature as a powerful being."

However, these results left an important question about the teleological bias unanswered. Years of schooling and academic practice did not extinguish physical scientists' tendencies to endorse inaccurate teleological ideas-mean test sentence endorsements were not at floor even in the unspeeded condition-nevertheless, the scientists' academic background certainly made their teleological propensity less pronounced. But was it their years of engagement in science, specifically, that afforded the scientists this advantage? A rich, coherent, theoretical understanding of the physical-causal mechanisms of nature would logically seem particularly effective at attenuating scientifically inaccurate teleological tendencies. However, it is also possible that there is a limit to the abatement of the teleological bias-one reached by prolonged academic training and immersion in analytic intellectual pursuits but unbreached even by possession of substantial, countervailing physical-causal scientific expertise. In Study 2, we explored this possibility by comparing the teleological biases of our professional scientists with an age-matched sample of active humanities scholars from various nonscience disciplines.

\section{Study 2}

\section{Method}

Participants. The final sample included 73 actively publishing humanities scholars (38 women, mean age $=39$ years, $S D=$ 4 , mean years since Ph.D. $=7$ years, $S D=4$ ) in classics, English, and history departments. We sampled the same institutions for humanities professors as for the scientists in Study 1 (e.g., Brown, Harvard, Yale). Once again, participants were required to be native English speakers, under 45 years, and without self-reported colorblindness or dyslexia. An additional 14 participants were excluded for failing to (a) respond to at least $75 \%$ of the test items and/or (b) accurately respond to at least $80 \%$ of the control items.

Table 4

Linear Regression Exploring the Effects of Beliefs in God and Mother Nature on Unwarranted Teleological Sentence Endorsement, Controlling for Condition

\begin{tabular}{|c|c|c|c|c|c|c|c|c|c|}
\hline \multirow[b]{2}{*}{ Variable } & \multicolumn{3}{|c|}{ College/Community } & \multicolumn{3}{|c|}{ Scientists } & \multicolumn{3}{|c|}{ Humanities } \\
\hline & $\beta$ & $t(224)$ & $p$ & $\beta$ & $t(76)$ & $p$ & $\beta$ & $t(68)$ & $p$ \\
\hline Condition & 0.24 & 3.98 & .000 & 0.35 & 3.60 & .001 & 0.22 & 2.33 & .023 \\
\hline Belief in God & 0.14 & 2.21 & .028 & 0.08 & 0.79 & .435 & 0.18 & 1.69 & .095 \\
\hline Belief in Mother Nature & 0.26 & 4.31 & .000 & 0.39 & 3.87 & .000 & 0.44 & 4.11 & .000 \\
\hline
\end{tabular}

Note. All models significantly predicted individual susceptibility to teleological error: college and community samples $R^{2}=.16, p<.001$; scientists $R^{2}=.30, p<.001$; humanities $R^{2}=.38, p<.001$. 
Procedure. The procedure was identical to Study 1 .

\section{Results}

Explanation judgment task. We compared humanities scholars' data with the scientists' data from Study 1. A 2 (group: scientists vs. humanities) $\times 2$ (condition: speeded vs. unspeeded) ANOVA on inaccurate test sentence endorsements revealed a main effect of condition, $F(1,149)=17.23, p<.001, \eta^{2}=.10$. Participants were more likely to endorse teleological test sentences under speeded $(M=30 \%, S D=22 \%)$ than unspeeded conditions $(M=18 \%, S D=15 \%)$. Because humanities scholars' performance did not differ from physical scientists' performance in either the speeded or unspeeded condition, there was neither a main effect of group $(p=.14)$ nor a Condition $\times$ Group interaction $(p=.73)$.

An independent samples $t$ test on inaccurate control sentence responses revealed no differences between speeded $(M=5 \%$, $S D=4 \%)$ and unspeeded $(M=4 \%, S D=3 \%)$ humanities participants, $t(71)=1.68, p=.10$ (see Figure 1). Heightened test sentence endorsement under speeded conditions therefore did not result from more general difficulties evaluating explanations at speed.

Individual differences. We next turned to explore whether scientists and humanities scholars showed equivalent levels of endorsement for the unwarranted teleological test sentences because their science knowledge, inhibitory control, and personal belief scores were equivalent. There were no differences between humanities scholars randomly assigned to the speeded and unspeeded conditions on any of the individual-difference measures, so their data were collapsed across conditions.

As Table 2 shows, the two participant groups had equivalently low levels of belief in God $(p=.93)$ and Mother Nature $(p=.19)$ and were also equivalent in inhibitory control performance ( $p=$ .46). Consistent with expectations, scientists had significantly greater scientific content knowledge: Scientists scored higher on assessments of both biological knowledge, $t(151)=3.11, p<$ .005 , and geoscience knowledge, $t(143)=8.62, p<.001$, with humanities scholars scoring no differently than the CC participants of Study 1 on the latter measure $(p=.98)$. The enhanced scientific knowledge of a professional scientist is therefore no more of a prophylactic against teleological error than extended training in the liberal arts.

Information-processing factors increasing humanities scholars' endorsements of unwarranted teleological explanations were examined. As Table 3 shows, a regression exploring the effect of inhibitory control abilities and scientific knowledge on test sentence endorsement (controlling for the effects of condition) was significant $\left(R^{2}=.32, p<.001\right)$. Poorer biological knowledge alone increased individual susceptibility to teleological error.

Finally, as Table 4 shows, a regression exploring the influence of God and Mother Nature beliefs on teleological sentence endorsement (controlling for the effects of condition) was also significant $\left(R^{2}=.38, p<.001\right)$. As in the scientist and CC groups, humanities scholars' teleological bias was predicted by beliefs in Mother Nature, and the correlation between this and belief in God was large $(R=.45, p<.001)$, once again confirming the quasireligious nature of the Mother Nature belief.

\section{Discussion}

In Study 2, we examined the teleological bias in a population whose level of academic training and analytic intellectual focus was equivalent to that of the scientists in Study 1, but whose expertise was not in the physical sciences. Consistent with their specialization in nonscience disciplines, the humanities scholars had significantly less biological and geoscience knowledge than the scientists of Study 1. Despite this, humanities scholars did not differ from physical scientists in their acceptance of scientifically unwarranted teleological explanations. The professional scientists' specialized training and practice in science therefore did not lead to additional mitigation of the teleological bias. There appears to be a limit on the revision of intuitive teleological bias that is reached by the analytic thinking and scientific literacy engendered by extended education and immersion in intellectual pursuits but remains unbreached even by possession of substantial, countervailing physical-causal scientific expertise. That the humanities scholars had lower scientific knowledge than the scientists but performed equivalently to them, and far better than the undergraduate and community samples of Study 1 , suggests that educational experience and training have power to abate the teleological bias. Nevertheless, the question regarding the source of the difference to $\mathrm{CC}$ samples remains open given that there may be other innate or early acquired cognitive style differences that distinguish those ultimately attracted to any kind of extended education and that are relevant to the expression of teleological belief (e.g., Gervais \& Norenzayan, 2012; Shenhav, Rand, \& Greene, 2012). Naturally higher levels of inhibitory control do not appear to be one of these differences, however. The Stroop scores of scientists, humanities scholars, and CC participants were equivalent.

As was the case for all participant groups in Study 1, stronger beliefs in Mother Nature predicted greater endorsement of test sentences. This suggests that the tendency toward teleological explanation is not an atheoretical stance or heuristic, but is underpinned by causal assumptions about agency in nature. This consistent result also serves to allay any residual concerns not addressed by control trial performance that participants' endorsements of teleological test sentences reflect little more than superficial linguistic effects: Systematic predictive associations between teleological endorsements and logically consistent theoretical beliefs about natural agency would not have been expected if test sentence endorsements simply resulted from linguistic pragmatics or low-level skim reading for content words.

\section{General Discussion}

The teleological bias has been suggested to persist as a lifelong cognitive default. Until now, however, research on promiscuous teleology has only been conducted with populations whose scientific knowledge and norms are insufficient to plausibly override this bias (e.g., Casler \& Kelemen, 2008; Kelemen, 1999b; Kelemen \& Rosset, 2009; Lombrozo et al., 2007). Physical scientists provide the strongest possible test of the hypothesis that teleological explanation is a tenacious tendency, in that scientists not only have mastery of the relevant content knowledge but are also unique in routinely and normatively adopting physical-causal modes of explanation and explicitly rejecting teleological ones in their professional lives. What this study shows is that even professional physical scientists endorse unwarranted teleological ex- 
planations about nature when placed under cognitive-processing restrictions. Moreover, although their bias is reduced relative to less schooled populations, their specialized scientific training and substantial knowledge base does no more to ameliorate their unwarranted teleological ideas than an extended humanities education. This suggests that there is a threshold to the conceptual revision of teleological ideas-one that even accomplished physical scientists do not breach. A broad teleological tendency therefore appears to be a robust, resilient, and developmentally enduring feature of the human mind that arises early in life and gets masked rather than replaced, even in those whose scientific expertise and explicit metaphysical commitments seem most likely to counteract it.

Patterns in personal beliefs measured in this study also help provide insight into the resilience of the teleological bias. Contrary to proposals that it is a primitive mode of interpreting the world with theoretical roots no deeper than a sensitivity to salient functional effects (Keil, 1992; Lombrozo et al., 2007; but see Kelemen \& Rosset, 2009), the present results suggest that the teleological stance has foundations in causal assumptions about the existence of agency in nature. As expected, given that it was measured explicitly, endorsement of the quasi-religious Mother Nature belief was generally low. Nevertheless, this belief consistently predicted unwarranted teleological endorsements within all four participant groups, converging with prior results suggesting that intuitive Gaia beliefs play a role in supporting the teleological bias (Kelemen \& Rosset, 2009). This finding suggests that educational attempts to counter scientifically unwarranted teleological beliefs must take into consideration underlying agentive and intentional conceptualizations of Nature, which are themselves likely to be stronger than revealed by the explicit measures used in the present research. It should also be noted that the science education challenges implied by connections between teleological and agentive causation are not insignificant given the credence that they lend to various theoretical claims that over evolutionary time, human minds have acquired intentionality and agency biases that are far more supportive of religion than science (Barrett, 2012; Bloom, 2007; Guthrie, 1993; Kelemen, 2004; Rosset, 2008). Consistent with this claim, additional regression analyses confirmed that, within every participant group tested (although more marginally for scientists), experimentally demonstrated teleological beliefs about nature significantly predicted explicit belief in God more than a basic capacity like inhibitory control, which has previously been argued to play a causal role in religious belief (Lindeman, Reikki, \& Hood, 2011). Even stronger relationships between teleological and religious beliefs might be expected when both are measured more implicitly (Järnefelt \& Kelemen, 2012a, 2012b).

In summary, the results of the present studies suggest that an orientation to explain nature in teleological terms is a developmentally persistent habit that remains unbroken even with years of specialized education. Prior research has yielded evidence that experts will resort to developmentally earlier, superficial perceptual strategies when making decisions under processing restrictions: On domain-specific judgment tasks, it has been found that biologists will resort to the "childlike" perceptual tactic of using physical cues of movement when categorizing plants and animals as "alive" (Goldberg \& Thompson-Schill, 2009). However, the present research reveals that there are developmentally continuous conceptual biases that affect thinking more globally and funda- mentally by broadly operating at the abstract, knowledgestructuring level of explanation (Carey, 1985; Chi, De Leeuw, Chiu, \& LaVancher, 1994; Keil, 2006). Such findings provide insight into the underlying nature of human cognition but carry broader practical implications as well. Explanations not only reflect present levels of conceptual and theoretical understanding but also actively influence subsequent conceptual acquisition and learning (Legare, Gelman, \& Wellman, 2010; Lombrozo, 2006; Murphy \& Medin, 1985). The presence of an underlying teleological bias may therefore have subtle enduring effects on our species' intellectual progress, creating impediments for truly mechanistic understanding and discovery even among those experts most expected to advance scientific knowledge of nature. At the same time, consistent with contemporary claims (e.g., Barrett, 2012; Bering, 2011; Bloom, 2007; Boyer, 2001; Kelemen, 2004), it may also serve to ensure that religious belief always remains cognitively natural and thus culturally resilient. Notions of purpose are central underpinnings of the world's religions, and the present research reveals not only that they are a natural default for the human mind but also that they are intimately connected to intuitions about agency. The formal beliefs and binding cultural effects of religion therefore appear to have robust roots in intuitive theoretical biases present from early childhood. The enduring effects of the human teleological bias on science and culture may be more profound than we realize.

\section{References}

Allen, C., Bekoff, M., \& Lauder, G. V. (1998). Nature's purposes: Analysis of function and design in biology. Cambridge, MA: MIT Press.

Anderson, D. L., Fisher, K. M., \& Norman, G. J. (2002). Development and evaluation of the conceptual inventory of natural selection. Journal of Research in Science Teaching, 39, 952-978. doi:10.1002/tea.10053

Aristotle (1930). Physica. W. D. Ross (Ed.) Oxford, England: Clarendon Press. (Original work published c. 350 BC)

Atran, S. (1995). Causal constraints on categories and categorical constraints on biological reasoning across cultures. In D. Sperber, D. Premack, \& A. J. Premack (Eds.), Causal cognition: A multidisciplinary debate: Symposia of the Fyssen Foundation (pp. 205-233). New York, NY: Clarendon Press/Oxford University Press.

Bacon, F. (2005). De augmentis scientarum. Ann Arbor, MI: Scholarly Publishing Office, University of Michigan Library. (Original work published 1623)

Barrett, J. L. (2012). Born believers: The science of children's religious belief. New York, NY: Free Press.

Barrow, J. D., \& Tipler, F. J. (1986). The anthropic cosmological principle. Oxford, England: Clarendon Press.

Bering, J. (2011). The belief instinct: The psychology of souls, destiny, and the meaning of life. New York, NY: W. W. Norton \& Company.

Bloom, P. (2007). Religion is natural. Developmental Science, 10, 147151. doi:10.1111/j.1467-7687.2007.00577.x

Boyer, P. (2001). Religion explained. The evolutionary origins of religious thought. New York, NY: Basic Books.

Burtt, E. A. (1932). Reason and nature. Philosophical Review, 41, 610620. doi: $10.2307 / 2179670$

Carey, S. (1985). Conceptual change in childhood. Cambridge, MA: MIT Press.

Carey, S. (1991). Knowledge acquisition: Enrichment or conceptual change? In S. Carey \& R. Gelman (Eds.), Epigenesis of mind: Studies in biology and cognition (pp. 257-291). Hillsdale, NJ: Erlbaum.

Casler, K., \& Kelemen, D. (2008). Developmental continuity in teleofunctional explanation: Reasoning about nature among Romanian Ro- 
mani adults. Journal of Cognition and Development, 9, 340-362. doi: 10.1080/15248370802248556

Chi, M. (1992). Conceptual change within and across ontological categories. In R. N. Giere (Ed.), Cognitive models of science: Volume 15. Minnesota studies in the philosophy of science (pp. 129-186). Minneapolis, MN: University of Minnesota Press.

Chi, M. T. H., De Leeuw, N., Chiu, M., \& LaVancher, C. (1994). Eliciting self-explanations improves understanding. Cognitive Science, 18, 439477.

Cohen, J. D., MacWhinney, B., Flatt, M. R., \& Provost, J. (1993). PsyScope: A new graphic interactive environment for designing psychology experiments. Behavioral Research Methods, Instruments, and Computers, 25, 257-271. doi:10.3758/BF03204507

Corey, M. A. (1993). God and the new cosmology: The anthropic design argument. Lanham, MD: Rowan \& Littlefield.

Diesendruck, G., \& Haber, L. (2009). God's categories: The effect of religiosity on children's teleological and essentialist beliefs about categories. Cognition, 110, 100-114. doi:10.1016/j.cognition.2008.11.001

DiYanni, C., \& Kelemen, D. (2005). Time to get a new mountain? The role of function in children's conceptions of natural kinds. Cognition, 97, 327-335. doi:10.1016/j.cognition.2004.10.002

Dunbar, K., Fugelsang, J., \& Stein, C. (2007). Do naïve theories ever go away? Using brain and behavior to understand changes in concepts. In M. Lovett \& P. Shah (Eds.), Thinking with data (pp. 193-206). Hillsdale, NJ: Erlbaum.

Evans, E. M., Legare, C., \& Rosengren, K. (2011). Engaging multiple epistemologies: Implications for science education. In M. Ferrari \& R. Taylor (Eds.), Epistemology and science education: Understanding the evolution vs. intelligent design controversy (pp. 111-139). New York, NY: Routledge.

Evans, J. St. B. T. (2008). Dual-processing accounts of reasoning, judgment, and social cognition. Annual Review of Psychology, 59, 255-278. doi:10.1146/annurev.psych.59.103006.093629

Evans, J. St. B. T. (2011). Dual-process theories of reasoning: Contemporary issues and developmental applications. Developmental Review, 31, 86-102. doi:10.1016/j.dr.2011.07.007

Ganguli, M., Snitz, B. E., Lee, C., Vanderbilt, J., Saxton, J. A., \& Chang, C. H. (2010). Age and education effects and norms on a cognitive test battery from a population-based cohort: The MonongahelaYoughiogheny Healthy Aging Team (MYHAT). Aging Mental Health, 14, 100-107. doi:10.1080/13607860903071014

Gervais, W. M., \& Norenzayan, A. (2012, April 27). Analytic thinking promotes religious disbelief. Science, 336, 493-496. doi:10.1126/ science. 1215647

Goldberg, R. F., \& Thompson-Schill, S. L. (2009). Developmental "roots" in mature biological knowledge. Psychological Science, 20, 480-487. doi:10.1111/j.1467-9280.2009.02320.x

Gopnik, A., \& Wellman, H. M. (1994). The theory theory. In L. A. Hirschfeld \& S. Gelman (Eds.), Mapping the mind: Domain specificity in cognition and culture (pp. 257-293). New York, NY: Cambridge University Press. doi:10.1017/CBO9780511752902.011

Greif, M. L., Kemler Nelson, D. G., Keil, F., \& Gutierrez, F. (2006). What do children want to know about animals and artifacts? Domain-specific requests for information. Psychological Science, 17, 455-459. doi: 10.1111/j.1467-9280.2006.01727.x

Guthrie, S. (1993). Faces in the clouds: A new theory of religion. New York, NY: Oxford University Press.

Hempel, C. G., \& Oppenheim, P. (1948). Studies in the logic of explanation. Philosophy of Science, 15, 135-175. doi:10.1086/286983

Järnefelt, E., \& Kelemen, D. (2012a, June). Creator in the clouds: Adults' spontaneous reasoning about the origin of nature. Paper presented at the International Association for the Cognitive Science of Religion, Aarhus, Denmark
Järnefelt, E., \& Kelemen, D. (2012b). The mind's design: Intuitive creationism and assumptions of purpose in nature. Manuscript in preparation.

Kahneman, D. (2011). Thinking fast and slow. New York, NY: Farrar, Giroux \& Strauss.

Keil, F. C. (1992). The origins of an autonomous biology. In M. Gunnar \& M. Maratsos (Eds.), Modularity and constraints in language and cognition: The Minnesota symposia (pp. 103-137). Hilldale, NJ: Erlbaum.

Keil, F. (1995). The growth of causal understandings of natural kinds. In D Sperber, D. Premack, \& A. J. Premack (Eds.), Causal cognition: A multidisciplinary debate (pp. 234-262). Oxford, England: Clarendon Press.

Keil, F. C. (2006). Explanation and understanding. Annual Review of Psychology, 57, 227-254. doi:10.1146/annurev.psych.57.102904 .190100

Kelemen, D. (1999a). The scope of teleological thinking in preschool children. Cognition, 70, 241-272. doi:10.1016/S0010-0277(99)00010-4

Kelemen, D. (1999b). Why are rocks pointy? Children's preference for teleological explanations of the natural world. Developmental Psychology, 35, 1440-1452. doi:10.1037/0012-1649.35.6.1440

Kelemen, D. (2003). British and American children's preferences for teleological-functional explanations of the natural world. Cognition, 88 201-221. doi:10.1016/S0010-0277(03)00024-6

Kelemen, D. (2004). Are children intuitive theists? Reasoning about purpose and design in nature. Psychological Science, 15, 295-301. doi: 10.1111/j.0956-7976.2004.00672.x

Kelemen, D. (2012). Teleological minds: How natural intuitions about agency and purpose influence learning about evolution. In K. S. Rosengren, S. K. Brem, E. M. Evans, \& G. M. Sinatra (Eds.), Evolution challenges: Integrating research and practice in teaching and learning about evolution (pp. 66-92). Oxford, England: Oxford University Press.

Kelemen, D., \& DiYanni, C. (2005). Intuitions about origins: Purpose and intelligent design in children's reasoning about nature. Journal of Cognition and Development, 6, 3-31. doi:10.1207/s15327647jcd0601_2

Kelemen, D., \& Rosset, E. (2009). The human function compunction: Teleological explanation in adults. Cognition, 111, 138-143. doi: 10.1016/j.cognition.2009.01.001

Legare, C. H., Gelman, S. A., \& Wellman, H. W. (2010). Inconsistency with prior knowledge triggers children's causal explanatory reasoning. Child Development, 81, 929-944. doi:10.1111/j.1467-8624.2010 .01443.x

Libarkin, J. C., \& Anderson, S. W. (2006). The Geoscience Concept Inventory: Application of Rasch analysis to concept inventory development in higher education. In X. Liu \& W. J. Boone (Eds.), Applications of Rasch measurement in science education (pp. 45-73). Fort Dodge, IA: JAM Publishers.

Lindeman, M., Reikki, T., \& Hood, B. (2011). Is weaker inhibition associated with supernatural beliefs? Journal of Cognition and Culture, 11, 231-239. doi:10.1163/156853711X570038

Lombrozo, T. (2006). The structure and function of explanations. Trends in Cognitive Sciences, 10, 464-470. doi:10.1016/j.tics.2006.08.004

Lombrozo, T., \& Carey, S. (2006). Functional explanation and the function of explanation. Cognition, 99, 167-204. doi:10.1016/j.cognition.2004.12 .009

Lombrozo, T., Kelemen, D., \& Zaitchik, D. (2007). Inferring design. Psychological Science, 18, 999-1006. doi:10.1111/j.1467-9280.2007 .02015.x

Mayr, E. (1985). The growth of biological thought. Cambridge, MA: Harvard University Press.

Millikan, R. G. (1989). In defense of proper functions. Philosophy of Science, 56, 288-302. doi:10.1086/289488

Murphy, G. L., \& Medin, D. L. (1985). The role of theories in conceptual coherence. Psychological Review, 92, 289-316. doi:10.1037/0033-295X .92.3.289 
Nagel, E. (1961). The structure of science. Indianapolis, IN: Hackett Publishing.

Neander, K. (1991). The teleological notion of function. Australasian Journal of Philosophy, 69, 454-468. doi:10.1080/00048409112344881

Perlman, M. (2004). The modern philosophical resurrection of teleology. The Monist, 87, 3-51.

Piaget, J. (1983). Piaget's theory. In P. Mussen (Ed.), Handbook of child psychology (4th ed., pp. 103-128). New York, NY: Wiley.

Rosset, E. (2008). It's no accident: Our bias for intentional explanations. Cognition, 108, 771-780. doi:10.1016/j.cognition.2008.07.001

Shenhav, A., Rand, D., \& Greene, J. (2012). Divine intuition: Cognitive style influences belief in God. Journal of Experimental Psychology: General, 141, 423-428. doi:10.1037/a0025391

Sober, E. (1984). Conceptual issues in evolutionary biology: An anthology. Cambridge, MA: MIT Press.

Stanovich, K., West, K., \& Toplak, M. (2011). The complexity of developmental predictions from dual process models. Developmental Review, 31, 103-118. doi:10.1016/j.dr.2011.07.003

Stern, Y., Gurland, B., Tatemichi, T. K., Tang, M. X., Wilder, D., \& Mayeux, R. (1994). Influence of education and occupation on the incidence of Alzheimer's disease. Journal of the American Medical Association, 271, 1004-1010. doi:10.1001/jama.1994.03510370056032
Stroop, J. R. (1935). Studies of interference in serial verbal reactions. Journal of Experimental Psychology, 18, 643-662. doi:10.1037/ h0054651

Talanquer, V. (2007). Explanations and teleology in chemistry education. International Journal of Science Education, 29, 853-870. doi:10.1080/ 09500690601087632

White, P. A. (1992). The anthropomorphic machine: Causal order in nature and the world view of common sense. British Journal of Psychology, 83, 61-96. doi:10.1111/j.2044-8295.1992.tb02425.x

Wicken, J. S. (1981). Causal explanations in classical and statistical thermodynamics. Philosophy of Science, 48, 65-77. doi:10.1086/288977

Wright, L. (1976). Teleological explanations: An etiological analysis of goals and functions. Los Angeles, CA: University of California Press.

Zaitchik, D., \& Solomon, G. E. A. (2008). Animist thinking in the elderly and in patients with Alzheimer's disease. Cognitive Neuropsychology, 25, 27-37. doi:10.1080/02643290801904059

Received February 12, 2012

Revision received September 5, 2012

Accepted September 10, 2012 